\title{
Corrigendum: Spatial-Temporal Analysis of the Heat and Electricity Demand of the Swiss Building Stock
}

\author{
Stefan Schneider ${ }^{1 *}$, Pierre Hollmuller ${ }^{1}$, Pascale Le Strat ${ }^{2}$, Jad Khoury', \\ Martin Patel ${ }^{3}$ and Bernard Lachal ${ }^{1}$ \\ 'Energy System Group, Institute for Environmental Sciences (ISE), Department F.-A. Forel for Environmental and Aquatic \\ Sciences (DEFSE), University of Geneva, Geneva, Switzerland, '2 Services industriels de Genève, Le Lignon, Switzerland, \\ ${ }^{3}$ Faculty of Science, Department F.-A. Forel for Environmental and Aquatic Sciences (DEFSE), Institute for Environmental \\ Sciences (ISE), University of Geneva, Geneva, Switzerland
}

Keywords: geo-depended energy demand, energy consumption by use, building classification, electric load curve, bottom-up model

\section{A corrigendum on}

Spatial-Temporal Analysis of the Heat and Electricity Demand of the Swiss Building Stock by Stefan, S. (2017). Front. Built Environ. 3:53. doi: 10.3389/fbuil.2017.00053

\section{OPEN ACCESS}

Edited and Reviewed by: Nahid Mohajeri, University of Oxford, United Kingdom

${ }^{*}$ Correspondence: Stefan Schneider stefan.schneider@unige.ch

Specialty section:

This article was submitted

to Sustainable Design and Construction, a section of the journal Frontiers in Built Environment

Received: 02 October 2017 Accepted: 03 October 2017 Published: 27 October 2017

Citation:

Schneider S, Hollmuller $P$, Le Strat $P$, Khoury J, Patel M and Lachal B (2017) Corrigendum: SpatialTemporal Analysis of the Heat and Electricity Demand of the Swiss Building Stock.

Front. Built Environ. 3:63. doi: 10.3389/fbuil.2017.00063

\section{ADDITION OF AN AUTHOR}

Pierre Hollmuller, Pascale Le Strat, Jad Khoury, Martin Patel and Bernard Lachal were not included as an author in the published article. The authors apologize for this error and state that this does not change the scientific conclusions of the article in any way.

\section{TEXT CORRECTION}

In the original article, there was an error (Acknowledgements require change after author addition). A correction has been made to Acknowledgments:

This research is part of the activities of SCCER FEEB\&D, which is financially supported by the Swiss Commission for Technology and Innovation (CTI). The authors thanks the Swiss Federal Statistical Office for the free access to the GWR database.

The authors apologize for this error and state that this does not change the scientific conclusions of the article in any way.

In the original article, there was an error (Author Contribution statement requires change after author addition).

A correction has been made to Author Contribution statement:

SS and PH are the main contributors of the methods described in section "Geo-Dependent Heat Demand." JK and BL contribute to section "Impact of Large-scale Retrofit on Heat Demand." PS and SS are the main contributors of the methods described in section "Geo-Dependent Electricity Demand." MP provided the access to the GEAK database. SS wrote the manuscript.

The authors apologize for this error and state that this does not change the scientific conclusions of the article in any way.

The author list, acknowledgements and author contributions of the original article has been updated. 
Conflict of Interest Statement: The authors declare that the research was conducted in the absence of any commercial or financial relationships that could be construed as a potential conflict of interest.

Copyright (c) 2017 Schneider, Hollmuller, Le Strat, Khoury, Patel and Lachal. This is an open-access article distributed under the terms of the Creative Commons
Attribution License (CC BY). The use, distribution or reproduction in other forums is permitted, provided the original author(s) or licensor are credited and that the original publication in this journal is cited, in accordance with accepted academic practice. No use, distribution or reproduction is permitted which does not comply with these terms. 